Rehabilitation

An international, multidisciplinary journal http://informahealthcare.com/dre

ISSN 0963-8288 print/ISSN 1464-5165 online

Disabil Rehabil, Early Online: $1-5$

(C) 2014 Informa UK Ltd. DOI: 10.3109/09638288.2014.942001 informa

healthcare

REVIEW PAPER

\title{
Contemporary vocational rehabilitation in Australia
}

\author{
Nicholas Buys ${ }^{1}$, Lynda R. Matthews ${ }^{2}$, and Christine Randall ${ }^{1}$ \\ ${ }^{1}$ Griffith Health Institute, Griffith University, Gold Coast, Australia and ${ }^{2}$ Ageing, Work and Health Research Unit, Faculty of Health Sciences, \\ The University of Sydney, Lidcombe, Australia
}

\begin{abstract}
Purpose: There is a strong connection between disability and decreased participation rates in the Australian labour market. Australian government policy recognises vocational rehabilitation as a key strategy to increase employment rates of people with disabilities. Methods: This paper examines current Australian disability employment policies and practices. It also reviews vocational rehabilitation competency research to identify knowledge and skill domains central to quality service provision, and explores the delivery of tertiary level vocational rehabilitation education. Results: Policy changes in Australia over the last decade have been aimed at addressing the unsustainable increase in disability benefits. In this context vocational rehabilitation services continue to be viewed as crucial in assisting people with disabilities to maintain employment and reduce disengagement. Competencies research has consistently identified vocational counselling, personal counselling, professional practice and case management as central to quality vocational rehabilitation service provision. Two competencies identified in recent research, workplace disability case management and workplace interventions and program management, reflect the centrality of vocational rehabilitation to disability management. Conclusions: Changes in the policy environment to reduce the number of disability pension recipients will inevitably lead to an increased demand for trained vocational rehabilitation personnel. Given the development of strong accreditation standards for vocational rehabilitation education and practice that underpin the provision of tertiary level rehabilitation counselling training programs, professionally qualified rehabilitation counsellors are ideally placed to address the complex employment needs of people with a disability.
\end{abstract}

\section{> Implications for Rehabilitation}

- It is important to understand changes that may occur in policy environments in terms of their impact on vocational rehabilitation service delivery for people with disabilities.

- Variable levels of training in the vocational rehabilitation sector result in people with complex needs not consistently receiving the services they need to access and maintain employment.

- Practitioners need to focus increasingly on individualized service delivery where the client has significant control over decisions about their rehabilitation program.

\section{Keywords}

Australia, employment, policy, vocational

\section{History}

Received 13 May 2014

Revised 2 July 2014

Accepted 2 July 2014

Published online 21 July 2014

\section{Introduction}

Approximately four million Australians, representing $18.5 \%$ of the population, reported having a disability in 2009, a decrease from 20\% in 2003 [1]. Successive Australian governments have grappled with the seemingly intractable problem of poor employment rates among people with a disability. Despite sustained economic growth and a buoyant labour market, Australia ranks 21 st of 29 OECD countries in terms of employment rates for people with a disability [2]. The labour force

Address for correspondence: Nicholas Buys, G40_8.68, Griffith Health Centre, Gold Coast Campus, Griffith University, Gold Coast, QLD 4222, Australia. Tel: +61 (0) 7567 89280. Fax: +61 (0) 7567 80798. E-mail: n.buys@griffith.edu.au participation rate for people with a disability was 54.3\% in 2009 compared to $82.8 \%$ for people without a disability [1] and it is notable that this difference has persisted over a 10 -year period. There is a strong relationship between disability and decreased participation rates in the Australian labour market - the participation rate of males is decreased by one-quarter and females by one-fifth compared to the same populations [3].

The cost to Australia of unemployment among people with a disability in terms of disability benefits is considerable. The number of Disability Support Pension recipients has increased $31 \%$ from 623926 in 2001 to 818850 in 2011 [4], with a projected cost of $\$ 14$ billion in 2011/2012 [5]. The reasons for this change include the increase in the ageing population, a greater focus on the identification of disabilities (particularly mental illness), lower mortality rates following accidents, decreases in the number of low-skilled jobs and the increase in the age pension age for women. Furthermore, it has been found that employers are 
less receptive to hiring people with a disability, particularly those in the older age categories and/or with low job skills [5].

Over the past few years there has been a notable attitude change whereby people with a disability are now viewed by governments as an untapped labour source that can meet the growing demand for skilled labour in Australia, as opposed to a marginalised "welfare group" [6]. As the Productivity Commission stated, "people with disabilities are seen as a resource rather than a cost centre", [5, p. 272]. Vocational rehabilitation is seen as a key strategy to increase employment rates of people with a disability, and significant increased funding has been allocated to VR services, within a policy framework that seeks to move people off the disability support pension and into work. Within this context, this paper explores current Australian disability employment policies and practices. It also explores recent vocational rehabilitation competency research and examines the delivery of tertiary level vocational rehabilitation education.

\section{Vocational rehabilitation: current policy and practice environment}

Australian research emphasises the importance of vocational rehabilitation as a strategy to maintaining connection with the labour market following the onset of disability [7]. Given the high level of disengagement of people on Disability Support Pension, providing employment support, combined with a more incentivised benefits structure, is currently viewed as the optimal approach to increasing employment rates of people with a disability [5]. To this end policy reforms have focussed on these two areas. This section will focus on policy reforms impacting vocational rehabilitation and the current service delivery environment.

Since 2006 there has been a welfare reform agenda in Australia, based on the notion of "mutual responsibility" whereby people with a capacity to work are required to seek work and, in return, the government provides employment assistance. Any person with a disability applying for income support is referred for a Job Capacity Assessment (JCA), through which barriers to work and appropriate interventions are identified and implemented to improve work capacity [8], including referral to a vocational rehabilitation program. Until 2010 the disability employment program consisted of disability open employment services and vocational rehabilitation. Open employment services were similar to supported employment in the US, providing intensive and ongoing support to obtain and keep a competitive job. In contrast, vocational rehabilitation services, comparable to those provided by the State/Federal VR system in the US, provided specialized services to gain and retain employment, without the need for long-term ongoing assistance. Mainstream employment services are also used when people with disability do not require specialized disability services or greater than six months post placement assistance.

In 2010, as part of the National Disability Strategy, disability employment services were redesigned into two new types of services within the Disability Employment Services (DES) Program. Disability management services provide job placement for people with a disability who do not require long-term support, but may need occasional flexible support to retain employment. Essential support services assist people with a permanent disability who require regular, ongoing support to maintain a job [9]. Vocational rehabilitation services are provided as part of an Employment Pathway Plan negotiated with clients and can include assessment, case management, job redesign, job matching and placement and ongoing support. In addition, the government provides a number of additional schemes to support vocational rehabilitation outcomes including:

(1) Wage Subsidy Scheme, which provides up to $\$ 1500$ as an incentive to employers to hire a person with a disability in open employment conditions;

(2) Enhanced Wage Subsidy Scheme, which provides up to $\$ 3000$ to employers who hire a long-term unemployed job seeker;

(3) Supported Wage System, which allows employers to pay a productivity based wage;

(4) Employment Assistance Fund to meet the cost of work-related modifications and services;

(5) Job Access Service (similar to the Job Accommodation Network in the US), which provides people with a disability, employers and service providers with information about services, financial assistance and workplace solutions that can promote employment outcomes;

(6) The National Disability Recruitment Coordinator Service, which works with large employers to create job vacancies for people with a disability; and

(7) Disability Support Pension Pilot, which offers wage subsidies to employers of up to $\$ 3,000$, once a pension recipient has been employed in a new job for at least eight hours per week for 26 weeks [10].

Disability employment services are provided by a range of profit and not-for-profit providers who are contracted by the federal government for a 5-year period from 2013 to 2018. The DES Program has a strong focus on job outcomes, with payment structures tailored to reward sustainable employment over a 12 -month period. Nearly 320000 people accessed disability employment services in 2011-2012 [11] at a cost of approximately $\$ 3.2$ billion [12]. However, the competitive and results oriented framework of the program has raised questions about rehabilitation providers focussing on clients who are easier to place, to the detriment of those with chronic and mental health conditions with more complex needs [13]. Regardless, it is evident that providers are "... grappling with the complex needs of participants with severe mental illness ...' [14, p. vii].

Australia also has a large number of Commonwealth and Statebased workers compensation and motor accident systems in which vocational rehabilitation is mandated. Over the last decade there have been legislative changes to these schemes, designed to encourage safer workplaces and the use of vocational rehabilitation, within a disability management framework. Employers are being required to take more responsibility for preventing and managing injuries, and to this end many larger organisations now employ dedicated disability managers. The success of these rehabilitation initiatives has been variable, with the cost of workplace injury estimated to be $\$ 60.6$ billion in 2008-2009, representing $4.8 \%$ of GDP [15].

\section{National Disability Insurance Scheme}

In July 2013 the Australian Government introduced the National Disability Insurance Scheme (NDIS) following a Productivity Commission Report [5], which found the disability support system was 'fragmented, underfunded, unfair and inefficient' and not meeting the individual needs of people living with a disability. The aim of the Scheme is to provide people with a significant disability with the supports necessary to enhance their independence and social and economic participation, but within a framework that enables them to exercise choice and control in the delivery of these supports [16]. The NDIS is being rolled out in stages. Sites in four Australian States (Barwon, Victoria; Hunter Region, New South Wales; South Australia; Tasmania) commenced in July 2013, with a further four sites due to 
commence from July 2014 (Australian Capital Territory; Barkly Region, Northern Territory; Perth Hills, Western Australia; Lower South West, Western Australia).

Although the aim of the NDIS is not to directly provide disability employment services per se, the Scheme will be responsible for supports that facilitate access and transition to work. These include:

- Supports related to daily living including personal care and transport to and from work;

- Supports to take part in work where the person has work capacity but is unable to access open employment;

- Individualised assistance to transition into work in areas such as communication skills, dress, attendance and workplace relationships [16].

These services are important in assisting people with a significant disability to maintain employment. However the NDIS has recently come under close scrutiny for cost overruns [17] and capacity of the disability sector to deliver the required services [18]. Further, within the context of a growing budget deficit, there are fears the current Australian government will reduce the funding for the Scheme.

\section{Vocational rehabilitation competency research}

One of the major criteria for developing strong accreditation requirements and clearer standards for vocational rehabilitation education and practice in Australia is an understanding of the contemporary knowledge and skills that are required to deliver professional vocational rehabilitation services in the various work settings identified earlier in this article. Historically, this information has been drawn from competency studies undertaken in the US that identified role, function and knowledge domains of rehabilitation counsellors, the profession that delivers the majority of vocational rehabilitation services $[19,20]$. While useful in the absence of local research, one perceived limitation in applying findings from the US studies to Australian settings has been the incongruity in important regulatory requirements between countries. Early Australian vocational rehabilitation competencies research [21] and more recent studies [22] have, however, had findings that identify similar knowledge and skill domains as those identified in the US. For example, both Biggs [21] and (Author's Own) [22] identified vocational counselling, personal counselling, professional practice, and case management as important factors in the delivery of vocational rehabilitation services in Australia despite the 14 year gap between studies.

The consistency of these domains over time suggests their significance to vocational rehabilitation practice in Australia. Additional domains identified in the (Author's Own) study [22], which was designed to capture the more recent expanded scope of vocational rehabilitation practice in Australia, included two disability management areas: workplace disability case management, and workplace interventions and program management. The identification of these additional areas is consistent with findings from disability management studies in the US [23] and provides evidence of the expansion of vocational rehabilitation services into rehabilitation and disability management in Australia.

With the increasing global focus on vocational rehabilitation, identifying common or core competencies that can inform learning standards for "global workers" has become an important focus for competencies research. A recent Australian-German research initiative has provided one of the first transnational comparative analyses of vocational rehabilitation knowledge and skill domains [24]. Using the same methodology and instrument, three common knowledge and skill domains were identified: vocational counselling, workplace disability case management, and workplace intervention and program management. There was a stronger focus on the delivery aspects of vocational rehabilitation and disability management by German rehabilitation professionals which is probably due to the legislation that defines vocational rehabilitation as a management task for the employer [25]. The focus of Australian rehabilitation professionals, however, was on rehabilitation practice which is consistent with the service delivery systems and legislative mandates in the area of vocational rehabilitation that have evolved since World War 1 [6]. While differences in skill and knowledge domains between Australia and Germany centred on the levels of specialisation in vocational rehabilitation practices in each country, the results confirm that professionals providing vocational rehabilitation are increasingly involved in disability management practice $[19,22]$. Importantly, the similarities in domains that were found in this study provide the first step in identifying the core knowledge and skills required for global workers and the first step in defining the content of global standards in vocational rehabilitation education.

\section{Tertiary level vocational rehabilitation education}

While there has been an increasing demand from industry peak bodies, government imperatives and professional associations for higher levels of education to deliver vocational rehabilitation services, this demand has varied across service delivery sectors. Private vocational rehabilitation services and CRS Australia (a Federal government operated provider) are more likely to employ tertiary qualified allied health professionals, such as rehabilitation counsellors, than federally funded DES providers. The DES sector continues to focus on Vocational Employment Training (VET) qualifications to address the needs of staff, many of whom have minimal experience and training in employment service delivery for people with a disability [13]. Pathways from industry experience and VET level training into postgraduate university level programs such as Graduate Certificates, Graduate Diplomas and Masters have existed for over a decade [26], but have had more uptake from staff employed in the workers' compensation and motor accident insurance areas than DES. This relatively slow move towards increased professionalism and in DES has had implications for addressing the needs of clients with more complex conditions or long-term support needs, as well as for the retention of staff.

At the university level, vocational rehabilitation has seen a shift to postgraduate qualifications in recent years. For example, universities with accredited rehabilitation counselling programs, including The University of Sydney and Griffith University, have abandoned undergraduate training in favour of Graduate Diploma and Masters level qualifications [6,27-30]. This shift has been driven by a number of factors, including the increasing demand for postgraduate training, accreditation requirements of professional bodies, global trends in rehabilitation counsellor education and employers perceptions regarding the benefit of life experience to practice. For example, in the area of accreditation, the new Rehabilitation Counselling Association of Australasia standards, based on the research described in the previous section, require a combination of knowledge and skills required for entry into the rehabilitation counselling profession that lends itself to postgraduate education. These knowledge and skills areas consist of the traditional vocational rehabilitation counselling competencies, as well as the newer disability management domains [6], which include disability program management skills in medium to large organisations [22].

Accreditation standards for Rehabilitation Counsellors in Australia have been further strengthened by increasing requirements of peak bodies such as the Heads of Workers' Compensation Authorities (HWCA) and government departments 
such as DEEWR. For example, the personal injury insurance sector now requires vocational rehabilitation services to be provided by professionals eligible for full membership of organisations such as RCAA and the Australian Society of Rehabilitation Counsellors (ASORC) [31], both of emphasise the need for university level qualifications in rehabilitation counselling for membership [32]. Australian government legislation also requires allied health professionals, such as Rehabilitation Counsellors, to complete key tasks such as Job Capacity Assessments [9,16,33].

In addition, the Australian Government has recently mandated that the tertiary education sector comply with Australian Qualifications Framework (AQF), which prescribes the learning outcomes, types of knowledge and length of each level of tertiary qualification (e.g. Diploma, Bachelors, Masters). For example, Level 9 programs (Masters) must demonstrate learning objectives that are more in line with the core knowledge and skills domains for rehabilitation counselling accreditation than Level 7 programs (Bachelor). Graduates from Bachelor programs should "have broad and coherent knowledge and skills for professional work", whereas Graduates from Masters programs should "have specialised knowledge and skills for research, and/or professional practice' [34, p. 13]. In this context, Master of Rehabilitation Counselling graduates are expected to demonstrate both multidisciplinary understanding relevant to practice in vocational rehabilitation, as well as discipline specific knowledge about areas such as vocational rehabilitation, psychosocial theory and workplace program management. They are also expected to have cognitive skills to critically evaluate the application of counselling theories and design appropriate services with an understanding of client needs and other stakeholder imperatives, as well as technical skills to utilise a broad range of client assessment data and independently conduct vocational and other formal assessments. The AQF will continue to impact vocational rehabilitation education in the future.

The changing mandates for vocational rehabilitation education in Australia present opportunities for the rehabilitation counselling profession to contribute more effectively to addressing the increasingly complex needs of clients in both DES and personal injury management programs. Stronger accreditation requirements and clearer standards for vocational rehabilitation education will provide graduates with additional skills and knowledge in both traditional areas such as vocational counselling and psychosocial interventions, as well as in more recent emerging areas such as disability program management. This will increase the contribution of the vocational rehabilitation workforce to reducing unemployment and non-participation among people with disability and serious injury.

\section{Conclusion}

Australian government policy over the last decade has recognised that people with disabilities are an important labour source in an increasingly tight labour market, and to this end, have implemented stricter tests to access disability benefits, while at the same time increasing incentives to find and keep a job. Vocational rehabilitation continues to be an important strategy within this policy framework. However, there is a variable level of training of people working in the vocational rehabilitation sector, and as consequence, there is some evidence that people with more complex needs are not receiving the services they require to access and maintain work. Recent rehabilitation counsellor competency studies have identified important knowledge domains for practice, providing the basis for the design of tertiary level curricula for professional training in this area.

\section{Declaration of interest}

The authors report no conflicts of interest. The authors alone are responsible for the content and writing of this article.

\section{References}

1. Australian Bureau of Statistics (ABS). Disability, ageing and carers, Australia, 4430.0. Canberra, ACT: Commonwealth of Australia; 2009.

2. OECD. Sickness, disability and work: breaking the barriers - a synthesis of findings across OECD countries. Paris, France: OECD; 2010.

3. Wilkins R. The effects of disability on labour force status in Australia. Austral Econ Rev 2004;37:359-82.

4. Macklin J. On the path to reform. Address to the Australian Network on Disability Conference, Hilton Hotel, Sydney; 2012 May 16.

5. Productivity Commission. Disability care and support, Report No. 54. Canberra, ACT: Commonwealth of Australia; 2011.

6. Matthews LR, Buys NJ, Crocker R, Degeneffe C. Overview of disability employment policy and rehabilitation practice in Australia: implications for rehabilitation counsellor education. Rehabil Educ 2007;21:241-50.

7. Polidano C, Vu H. Labour market impacts from disability onset. Melbourne Institute Working Paper No. 22/12. Melbourne, VIC: Melbourne Institute of Applied Economic and Social Research; 2012.

8. Commonwealth of Australia. Welfare to work budget measures. Canberra, ACT: Commonwealth of Australia; 2005.

9. Australian Government. 2013. Guide to social security law: 1.1.J.20 Job capacity assessor. Available from: http://guidesacts.fahcsia.gov.au/guides_acts/ssg/ssguide-1/ssguide-1.1/ssguide-1.1.j/ pc_13658.html [last accessed 16 Sep 2013].

10. Department of Education, Employment and Workplace Relations (DEEWR). Disability employment services. 2013. Available from: http://deewr.gov.au/disability-employment-services [last accessed 16 Sep 2013].

11. Australian Institute of Health and Welfare (AIHW). Disability support services: services provided under the National Disability Agreement, 2011-2012. Bulletin 118. Cat. No. AUS 173. Canberra, ACT: AIHW; 2013.

12. Department of Education, Employment and Workplace Relations (DEEWR). Disability employment services flexible, tailored employment assistance fact sheet. 2013. Available from: http://deewr.gov.au/information-products-and-guides-disability-employment-services [last accessed 8 Sep 2013].

13. Byrnes C, Lawn S. Disability employment services in Australia: a brief primer. Austral J Rehabil Counsel 2013;19:46-56.

14. Department of Education, Employment and Workplace Relations. Evaluation of disability employment services interim report, Reissue March 2012. Canberra, ACT: Department of Education, Employment and Workplace Relations; 2012.

15. Safe Work Australia. The cost of work-related injury and illness for Australian employers, workers, and the community, 2008-09. Canberra, ACT: Safe Work Australia; 2012.

16. Australian Government. National Disability Insurance Scheme (Supports for Participants) Rule 2013. Canberra, ACT: Commonwealth of Australia; 2013.

17. Shanahan D. NDIS trial costs blow-out by $30 \%$ : scheme hits $\$ 46,000$ a head [Internet]. 2014. Available from: http://www.theaustralian.com.au/national-affairs/policy/ndis-trial-costs-blow-out-by-30pcscheme-hits-46000-a-head/story-fn59nokw-1226868205305\#mmpremium [last accessed 28 Apr 2014].

18. Wilson L. Alarm bells in secret NDIS report. 2014. Available from: http://www.news.com.au/lifestyle/health/alarm-bells-in-secret-ndisreport/story-fneuz9ev-1226897740587 [last accessed 28 Apr 2014].

19. Leahy MJ, Chan F, Saunders JL. Job functions and knowledge requirements of certified rehabilitation counselors in the $21 \mathrm{st}$ century. Rehab Counsel Bull 2003;46:66-81.

20. Leahy MJ, Shapson PR, Wright GN. Rehabilitation counselor competencies by role and setting. Rehab Counsel Bull 1987;31: 94-106.

21. Biggs HC. A validation of the rehabilitation skills inventory in four Australasian rehabilitation organisations and its relationship with occupation measures. Unpublished Doctoral Dissertation, Massey University, New Zealand; 1996. 
22. Matthews LR, Buys NJ, Randall C, et al. Evolution of vocational rehabilitation competencies in Australia. Int $\mathrm{J}$ Rehabil Res 2010;33:124-33.

23. Rosenthal DA, Hursh N, Lui J, et al. A survey of current disability management practice. Rehab Counsel Bull 2007;50:76-86.

24. Matthews L, Buys N, Randall C, et al. A comparative study of the job tasks, functions, and knowledge domains of rehabilitation professionals providing vocational rehabilitation services in Australia and Germany. Rehabil Couns Bull. 2014. [Epub ahead of print]. doi: 10.1177/0034355213504304.

25. Niehaus M, Marfels B. Competencies and tasks of disability management professionals in Germany. Int $J$ Disabil Manage 2010;5:67-72.

26. Griffith University. Graduate certificate in case management. Available from: https://www148.griffith.edu.au/programs-courses/ Program/OverviewAndFees?ProgramCode $=3050 \quad$ [last accessed 16 Sep 2013].

27. Australian Society of Rehabilitation Counsellors (ASORC). ASORC accredited rehab counselling courses. 2013. Available from: http:// www.asorc.org.au/education/asorc-accredited-courses [last accessed 16 Sep 2013].

28. Griffith University. Programs and courses: human Services. 2013 Available from: http://www.griffith.edu.au/health/schoolhuman-services-social-work/programs-courses [last accessed 16 Sep 2013].
29. Rehabilitation Counselling Association of Australasia (RCAA) (n.d.). Accreditation manual for rehabilitation counselling education programs. (adopted by RCAA in 2013). Available from: www.rcaa.org.au [last accessed 16 Sep 2013].

30. University of Sydney. Rehabilitation counselling - courses and careers. 2013. Available from: http://sydney.edu.au/health-sciences/ disciplines/rehabilitation-counselling/courses-careers.shtml [last accessed 16 Sep 2013].

31. Heads of Workers Compensation Authorities (HWCA). Nationally consistent approval framework for workplace rehabilitation providers. 2012. Available from: http://www.hwca.org.au/documents/Guide\%20-\%20Nationally\%20Consistent $\% 20$ Approval\%20Framework\%20for\%20Workplace\%20Rehabilitation \% 20Providers.pdf [last accessed 16 Sep 2013].

32. Rehabilitation Counselling Association of Australasia (RCAA). Membership information. 2013. Available from: http://www.rcaa. org.au/membership-information [last accessed 16 Sep 2013].

33. Welfare Rights Centre [Internet]. Job capacity assessments. 2013. Available from: http://www.wrcqld.org.au/employment-services/ what-you-need-to-know/job-capacilty-assessments.html [last accessed 16 Sep 2013].

34. Australian Qualifications Framework (AQF) Council. Australian qualifications framework (2nd ed.). 2013. Available from: http:// www.aqf.edu.au/wp-content/uploads/2013/05/AQF-2nd-EditionJanuary-2013.pdf [last accessed 16 Sep 2013]. 